\title{
Diurnal panic attacks with and without nocturnal panic attacks: are there some phenomenological differences?
}

\author{
Ataques de pânico diurnos com e sem ataques de \\ pânico noturnos: existem algumas differenças \\ fenomenológicas?
}

\author{
Fabiana L Lopes, ${ }^{1}$ Antonio E Nardi, ${ }^{1}$ Isabella Nascimento, ${ }^{1}$ \\ Alexandre M Valença, ${ }^{1}$ Marco A Mezzasalma, ${ }^{1}$ \\ Rafael C Freire, ${ }^{1}$ Walter A Zin ${ }^{2}$
}

\begin{abstract}
Objective: To compare nocturnal and diurnal panic attacks in a cross-sectional study and in a longitudinal prospective short-term follow-up. Methods: We selected 57 panic disorder (PD) subjects (DSM-IV) and rated them with the Panic Disorder Severity Scale (PDSS) at baseline and after 30 days of treatment with nortriptyline, and with the Eysenck Personality Inventory and the Brown Attention Deficit Disorder (ADD) Scale at baseline. Results: The sample was divided into a nocturnal and diurnal panic attack (NDPA) group - 57.9\% ( $n=33)$ - and a diurnal panic attack (DPA) group - 42.1\% $(n=24)$. The groups showed a similar mean age at onset of PD and a pattern of prominent respiratory symptoms. The PDSS did not differ between the groups following short-term treatment ( $p=0.451$ ). There were also neither significant differences in Neuroticism $(p=0.094)$ and Extroversion $(p=0.269)$ nor in the Brown ADD Scale ( $p=0.527)$. Conclusion: In our study, patients with both nocturnal and diurnal panic attacks showed similar features in their phenomenology and short-term outcome when compared to pure diurnal panic attacks patients.
\end{abstract}

Keywords: Panic disorder/drug therapy; Sleep disorders; Psychiatric status rating scales; Attention deficit disorder with hyperactivity; Nortriptyline/therapeutic use; Cognition; Personality inventory

\begin{abstract}
Resumo
Objetivo: Comparar ataques de pânico noturnos e diurnos em um estudo de acompanhamento prospectivo de curto prazo Métodos: Selecionamos 57 indivíduos com transtorno do pânico (TP) segundo o DSM-IV e os classificamos com a Panic Disorder Severity Scale (PDSS) na linha de base e após 30 dias de tratamento com nortriptilina, e com o Eysenck Personality Inventory e a escala Brown Attention Deficit Disorder $(A D D)$ na linha de base. Resultados: A amostra foi dividida em um grupo com ataques de pânico noturnos e diurnos (NDPA) - 57,9\% $(n=33)$ - e um grupo com ataques de pânico diurnos $(D P A)-42,1 \%(n=24)$. Os grupos tiveram idades médias de início de transtorno do pânico e um padrão de sintomas respiratórios proeminentes similares. A Panic Disorder Severity Scale não apresentou diferenças entre os grupos após tratamento de curto prazo $(p=0,451)$. Tampouco houve diferenças significativas em Neuroticismo ( $p=0,094)$ e Extroversão $(p=0,269)$ e na escala Brown Attention Deficit Disorder $(p=0,527)$. Conclusão: Em nosso estudo, os pacientes com ataques de pânico noturnos e diurnos tiveram características similares quanto aos seus resultados fenomenológicos e resultados em curto prazo em comparação com pacientes que tiveram somente ataques diurnos de pânico.
\end{abstract}

Descritores: Transtornos de pânico/farmacoterapia; Transtornos do sono; Escalas de graduação psiquiátrica; Transtorno da falta de atenção com hiperatividade; Nortriptilina/uso terapêutico; Cognição; Inventário de personalidade

\footnotetext{
1 Panic and Respiration Laboratory, Institute of Psychiatry, Universidade Federal do Rio de Janeiro (UFRJ), Rio de Janeiro (RJ), Brazil

2 Respiration Physiology Laboratory, Carlos Chagas Filho Biophysics Institute, Universidade Federal do Rio de Janeiro (UFRJ), Rio de Janeiro (RJ), Brazil
}

Financing: Conselho Nacional de Desenvolvimento Científico e Tecnológico (CNPq), Grant 300500/93-9

Conflicts of interests: None

Submitted: 5 July 2004

Accepted: 29 November 2004

\section{Correspondence}

Fabiana Leão Lopes

Panic and Respiration Laboratory

Federal University of Rio de Janeiro

R. Visconde de Pirajá, 407 / 702

22410-003 Rio de Janeiro, RJ, Brazil

Phone. (55 21) 2521-6147 Fax. (55 21) 2523-6839

E-mail: fllopes@predialnet.com.br 


\section{Introduction}

In recent years, considerable attention has been given to elucidate the phenomenology of panic attacks. ${ }^{1-2}$ The data have led to increased recognition of panic attacks as a multidimensional phenomenon with heterogeneity in terms of their phenomenology. ${ }^{2}$ Several typologies ${ }^{2-5}$ have been developed in the last decade in order to improve the description of the various cluster of symptoms in panic disorder (PD).

Biber, Alkin point out that PD patients of the prominent respiratory symptoms subtype were more sensitive to $\mathrm{CO}_{2}$ inhalation, had a longer duration of illness, had more severe panic and phobic symptoms, and were more likely to be heavier smokers. ${ }^{5}$ It was also suggested that PD patients with prominent respiratory symptoms are associated with increased rates of spontaneous and nocturnal panic attacks. ${ }^{5}$ Nocturnal panic attacks are a common clinical condition occurring with regularity in 18 to $45 \%$ of PD patients. ${ }^{6-8}$ Nocturnal panic attacks are characterized by sudden awakening from sleep in a state of panic, defined as an abrupt and quick period of intense fear or discomfort accompanied by cognitive and physical symptoms of arousal. Nocturnal panic does not refer to waking from sleep and panicking after a period of waking time. Nor does nocturnal panic refer to nighttime arousals induced by nightmares. Nocturnal panic, as with unexpected diurnal panic attacks, occurs without an obvious trigger.

Stein et al, in a polysomnographic study of 14 PD patients, found evidence of respiratory irregularities in a subgroup of patients with recent panic attacks during sleep and suggested that nocturnal panic attacks might be a variant of panic disorder. ${ }^{8-10}$

An overlap of symptomatological profile between nocturnal panic attacks and sleep apnea syndrome has been observed.11-12 Among the symptoms common to both syndromes were the sensations of choking or drowning associated with nocturnal awakening, initial and middle insomnia, and sudoresis. On the other hand, among the common diurnal symptoms were drowsiness and cognitive complaints, such as difficulty in concentrating, mild forgetfulness, and a pattern of frontal headache. ${ }^{12}$ In a survey of 301 sleep apnea patients, Edlund et al. demonstrated that obstructive sleep apnea may cause nocturnal panic attack symptoms and suggested that groups of PD patients should be studied for signs and symptoms of sleep apnea syndrome. ${ }^{11}$ Based on data related to nocturnal panic attacks, there appear to be both similarities and differences from sleep apnea disorder. Nocturnal panic attacks have been found to occur during light, non-REM sleep and during delta sleep. Apneas typically occur in stages 1 and 2 of sleep and during rapid eye movement (REM) sleep. The sleep of PD patients is characterized by increased delta sleep compared to the reduced delta sleep in individuals with obstructive apnea. However, as occurs in obstructive apnea, PD patients exhibit excessive movement during the night.

Nocturnal panic must be established as a separate entity, distinguished from night terrors, sleep paralysis, and dreaminduced anxiety. Night terrors are characterized by sudden awakening from delta sleep, $1 / 2$ hour to 3 hours after falling asleep, in a state of confused autonomic arousal. Night terrors resemble nocturnal panic in terms of the autonomic arousal and the phase of sleep during which they occur. These two entities seem to be different in terms of the return to peaceful sleep and memory of the event. Nocturnal panics are described as being vividly recalled and rarely followed by a quick return to sleep. By the other way, sleep paralysis differs from nocturnal panic attack in terms of the reported inability to move, and appearance of being in a deep sleep. Clinical evidence suggests that patients usually sit up or get out of bed while experiencing nocturnal panic attacks. Dream-induced anxiety attacks occur during REM sleep, during later parts of the night when dreams are longer, vivid, and more emotional. Also, the major difference between dream-induced anxiety and the nocturnal panic attack would be the recall of a dream.

Several studies suggest that the presence of nocturnal panic attack is related to increased severity of the panic

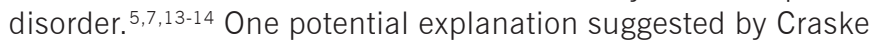
et al, is that it might represent a more severe form along the panic disorder spectrum. ${ }^{15}$

Shapiro, Sloan suggested that diurnal and nocturnal panic attacks develop along different evolutionary pathways. ${ }^{10}$ Biological factors, such as an autonomic nervous system (ANS) dysfunction, might be a crucial aspect in the case of nocturnal panic attacks, while psychological and cognitive factors may function as an initial stimulus for diurnal panic attacks. ${ }^{10}$ It is also argued that some pharmacological agents specifically addressed to the ANS dysfunction may be more effective in patients with nocturnal panic attacks, while behavioral or cognitive strategies may be optimal for patients with diurnal panic attacks. ${ }^{10}$

The present study was aimed at comparing the phenomenological features of patients with both nocturnal and diurnal panic attacks to those of patients with only diurnal panic attacks, including respiratory symptoms, cognitive aspects and personality traits. We first hypothesized that the nocturnal and diurnal panic attack group would present a more severe clinical picture compared to the only diurnal panic group (i.e., increased occupational, social and cognitive impairment; more respiratory symptoms; and higher rates of comorbid psychiatric disorders). The second hypothesis was that the daytime group would present increased neuroticism scores. Since sleep apnea syndrome and nocturnal panic attacks share common symptoms we also aimed at investigating some cognitive impairment among PD subjects through the Brown ADD Scale.

\section{Methods}

Fifty-seven outpatients with panic disorder, diagnosed according to the Structured Clinical Interview Diagnostic (SCID-I) ${ }^{16}$ for Diagnostic and Statistical Manual for mental Disorders (DSM-IV) ${ }^{17}$ were included. The patients were selected from a sample of individuals regularly treated at the Panic and Respiration Laboratory of the Institute of Psychiatry, Universidade Federal do Rio de Janeiro. To be included, subjects should age between 18 and 65 years and be in good health. Exclusion criteria included pregnancy or lactation; presence of psychotic, bipolar and cognitive disorders, including delirium, dementia, amnestic disorder, and mental disorders due to a general medical condition not otherwise specified; evidence of current or past substance abuse; medical history of respiratory disease; and overweight or obesity (BMI > 25). After receiving a complete description of the study, subjects gave their informed consent. The protocol, according to the guidelines described in the Declaration of Helsinki, was approved by our local Ethics Committee.

The study design consisted of a cross-sectional study at the baseline and a longitudinal follow-up covering the 30-day 
period. We performed a semi-structured clinical interview and divided the sample into: 1) a diurnal panic attacks group DPA - $(n=24,18$ women and 6 men; mean age = 37.4, \pm 11.9), and 2) a nocturnal and diurnal panic attacks group - NDPA - ( $n=33,25$ women and 8 men; mean age $=39.6$, \pm 9.8). We did not include a sample of patients with isolated nocturnal panic attacks due to the rarity of such patients in our total sample $(n=1)$.

Each subject was checked for respiratory symptoms according to the outlines proposed by Briggs et al. ${ }^{4}$ Patients reporting at least four of the following five symptoms - shortness of breath, choking/smothering sensations, fear of dying, chest pain/ discomfort, and tingling/numbness - were classified as the prominent respiratory symptoms. The subjects with less than four symptoms were classified as a residual group, or nonrespiratory symptoms group. ${ }^{4}$

All subjects were assessed using the Panic Disorder Severity Scale (PDSS). ${ }^{18}$ The instrument was employed by well-trained research staff and the procedure took from 15 to 20 minutes. It was used in the original version. ${ }^{18}$ The scale consists of items rated on a five-point Likert scale, and includes frequency of panic attacks and limited symptom episodes (LSE's), distress caused by panic attacks and LSE's, anticipatory anxiety, agoraphobic fear/avoidance, panicrelated sensation fear/avoidance, and work and social impairment. This scale has adequate internal consistency, excellent inter-rater agreement, good discriminant validity and sensitivity to change. ${ }^{19-20}$

Personality traits such as neuroticism and extraversion were assessed by the Eysenck Personality Inventory, ${ }^{21}$ applied to all subjects at baseline. This questionnaire is composed by three blocks - neuroticism, extroversion, and lying scores. It was translated and a back-translation was also performed. It was not validated in Portuguese.

The Brown Attention Deficit Disorder (ADD) Scale was used to compare the daytime cognitive and behavioral patterns between the groups. ${ }^{22}$ The scale is composed of five blocks organization and working activation; sustained attention; energy and effort maintenance; self-regulation of affect interference; and working memory - and presents good specificity and poor sensitivity. ${ }^{23}$ We used the measure in a self-reported way. It is important to mention that although the scale is not validated in Portuguese, it was translated and a back-translation performed. The literature is starting to give importance to this scale in different disorders from ADHD. We are beginning to use it in PD patients due to the executive deficit hypothesis, but it will probably start to be used in other disorders in the short term.

All subjects were treated with escalating doses of nortriptyline, varying from 10 to $150 \mathrm{mg} /$ day. The dosage increases were based on clinical judgment and on the adverse events' profile. Subjects were not taking benzodiazepines, and the wash-out comprised the period of two weeks for benzodiazepines and tricyclics, 5 weeks for SSRI's, and 1 week for other psychotropic drugs. Due to the fact that PD patients are hypersensitive to the adverse events of drugs, we decided that when subjects presented remission of their panic attacks under the highest tolerated dosage of the drug, it was then stabilized. The presence of other symptoms of PD in the 30-day follow-up period (such as anticipatory anxiety, high level of agoraphobia and/or social impairment) contributed to our sense of cognitive behavior therapy indication. Patients were seen in weekly visits and were reassessed after a 30-day period, when they were evaluated by PDSS. All subjects continued taking the medication after the 30-day evaluation.

\section{Data analyses}

Differences between the DPA and NDPA groups regarding sex, prominent respiratory symptoms, and comorbidities were tested with chi-square analyses. The data were not normally distributed, in spite of attempts to fit them in a normal curve, such as logarithmic conversion. Non-parametric statistical tests were used to compare the groups. Comparisons between the groups with regard to age, scores on the Brown ADD Scale and on the Panic Disorder Severity Scale at the baseline were obtained by the Mann-Whitney Test. The improvement of each group, assessed through the comparison of PDSS results at the end of treatment to those at baseline, was calculated using the Wilcoxon Signed Ranks Test. Fisher exact test was used to compare the patients submitted to cognitive behavioral therapy, between the groups. All reported $p$ values are for two-tailed tests of significance. We used the Epi-Info program and the statistical significance level was set at $5 \%$.

\section{Results}

\section{Demographics}

The majority of the sample was composed by women (NDPA, 75.6\%; DPA, 76.5\%; $p=0.954)$. The current mean age was $39.6(S D=9.8)$ and 37.4 years $(S D=11.9)$ for NDPA and DPA, respectively ( $p=0.317)$. The mean age at onset of panic disorder was 32.58 for NDPA and 33.50 for DPA group $(p=0.317)$. There were no demographic differences between the two groups.

\section{Respiratory symptoms}

There was no significant difference between the groups regarding the prominent respiratory symptoms - Figure 1 .

\section{Comorbidities}

Comorbidity rates for the DPA group were: $25 \%(n=6)$ major depression, $12.5 \%(n=3)$ specific phobia, $8.3 \%$ $(n=2)$ social phobia, $4.2 \%(n=1)$ generalized anxiety disorder, and 4.2\% $(n=1)$ specific phobia and generalized anxiety disorder. For the NDPA group, the comorbidity rates were: $21.2 \%(n=6)$ major depression, $6.1 \%(n=2)$ specific phobia, 3.1\% $(n=1)$ generalized anxiety disorder and 3.1\% $(n=1)$ major depression and specific phobia. Fisher's exact test indicated no group differences in terms of current comorbid diagnosis $(p=0.546)$.

\section{Clinical course}

Scores on the PDSS did not differ between the groups either at baseline or under treatment - Figure 2. The clinical patterns that compose the PDSS and its outcome are presented on Table 1 . The doses of nortryptiline employed were not significantly different between the DPA and the NDPA groups (mean dose \pm SD: $52 \pm 32 \mathrm{mg} /$ day vs. $42 \pm 32 \mathrm{mg} / \mathrm{day}$, for the DPA and the NDPA respectively). On the other hand, $25 \%(n=6)$ of subjects from the DPA group had to be submitted to cognitive behavioral therapy, compared to $12.5 \%(n=4)$ from the NDPA group ( $p=0.29$ ).

There were also no significant differences between the groups with regard to personality traits - Neuroticism (18.7 \pm 4.6 vs. 


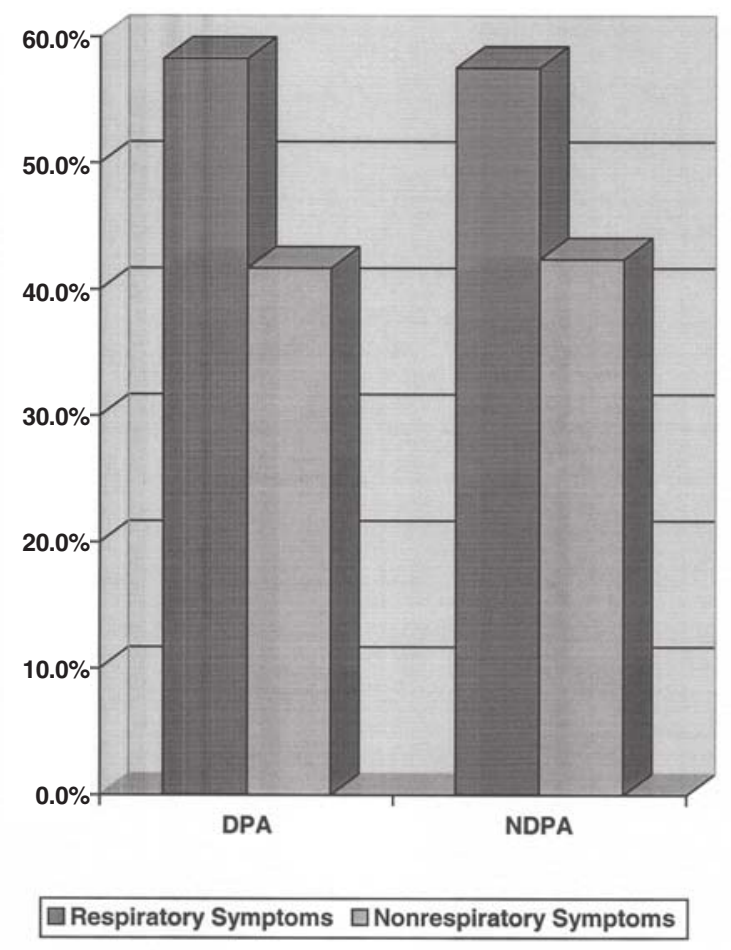

DPA - Daytime Panic Attacks; NDPA - Nocturnal and Daytime Panic Attack Chi-square $=10.11$, d. f. $=1, p=0.954$

Figure 1 - Symptomatological Profile (\%) of Nocturnal and Daytime Panic Attack (NDPA) group and Daytime Panic Attacks (DPA) group. Comparing the prevalence of respiratory and non-respiratory panic disorder subtypes in both groups

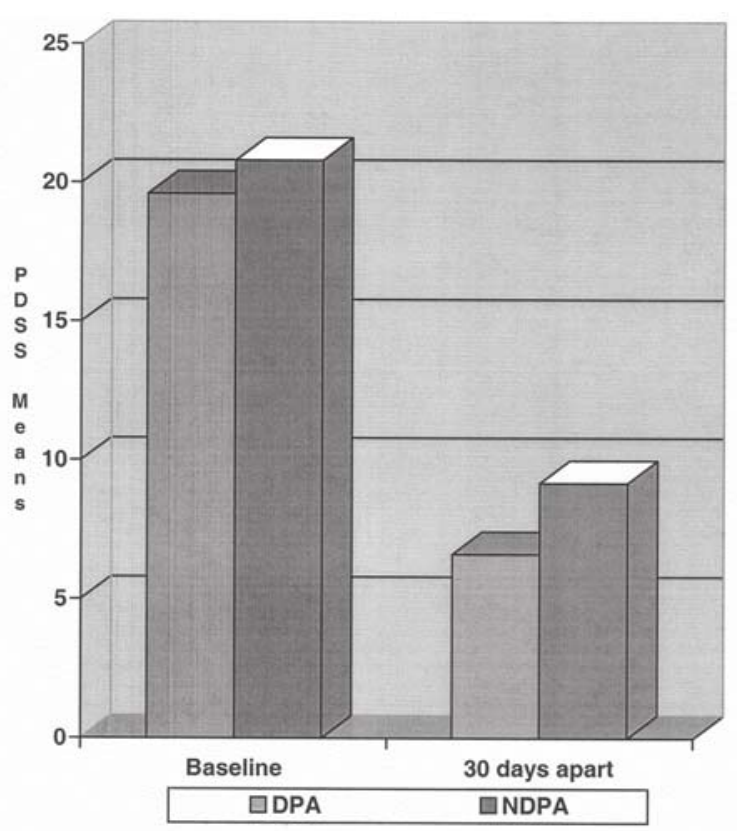

PDSS - Panic Disorder Severity Scale

DPA - Daytime Panic Attacks; NDPA - Nocturnal and Daytime Panic Attack $p=0.481$, Mann-Whitney Rank Sum Test

Figure 2 - Panic Disorder Severity Scale total score: Severity (baseline) $X$ Outcome (after 30 days)

Table 1 - Panic Disorder Severity Scale scores: clinical patterns vs. outcome (after 30 days) in DPA (Daytime Panic Attacks) and NDPA (Nocturnal and Daytime Panic Attack)

\begin{tabular}{|c|c|c|c|c|c|c|c|}
\hline & & \multicolumn{3}{|c|}{ NDPA } & \multicolumn{3}{|c|}{ DPA } \\
\hline & & Baseline & End of Treatment & p value* & Baseline & End of Treatment & p value* \\
\hline \multirow[t]{3}{*}{ Frequency } & $25 \%$ & 3.0 & 1.0 & .000 & 2.0 & 0.0 & .000 \\
\hline & Median & 4.0 & 1.0 & & 3.0 & 1.0 & \\
\hline & $75 \%$ & 4.0 & 1.0 & & 4.0 & 1.0 & \\
\hline \multirow[t]{3}{*}{ Distress } & $25 \%$ & 3.0 & 1.0 & .000 & 3.0 & 0.0 & .000 \\
\hline & Median & 4.0 & 2.0 & & 4.0 & 1.0 & \\
\hline & $75 \%$ & 4.0 & 3.0 & & 4.0 & 2.0 & \\
\hline \multirow[t]{3}{*}{ Anticipatory anxiety } & $25 \%$ & 3.0 & 1.0 & .000 & 2.0 & 0.5 & .000 \\
\hline & Median & 3.0 & 1.0 & & 3.5 & 1.0 & \\
\hline & $75 \%$ & 4.0 & 2.0 & & 4.0 & 1.5 & \\
\hline \multirow{3}{*}{$\begin{array}{l}\text { Situational phobic } \\
\text { avoidance }\end{array}$} & $25 \%$ & 2.0 & 1.0 & .000 & 2.0 & 1.0 & .000 \\
\hline & Median & 2.0 & 1.0 & & 3.0 & 1.0 & \\
\hline & $75 \%$ & 4.0 & 2.0 & & 4.0 & 2.0 & \\
\hline \multirow{3}{*}{$\begin{array}{l}\text { Physical sensations' } \\
\text { phobic avoidance }\end{array}$} & $25 \%$ & 1.0 & 0.0 & .001 & 0.5 & 0.0 & .001 \\
\hline & Median & 2.0 & 1.0 & & 2.0 & 1.0 & \\
\hline & $75 \%$ & 3.0 & 1.0 & & 3.0 & 1.0 & \\
\hline \multirow{3}{*}{$\begin{array}{l}\text { Impairment in work } \\
\text { functioning }\end{array}$} & $25 \%$ & 3.0 & 0.0 & .000 & 2.0 & 0.0 & .000 \\
\hline & Median & 3.0 & 1.0 & & 3.0 & 0.5 & \\
\hline & $75 \%$ & 4.0 & 2.0 & & 4.0 & 1.0 & \\
\hline \multirow{3}{*}{$\begin{array}{l}\text { Impairment in social } \\
\text { functioning }\end{array}$} & $25 \%$ & 2.0 & 0.0 & .000 & 2.0 & 0.0 & .000 \\
\hline & Median & 3.0 & 1.0 & & 3.5 & 1.0 & \\
\hline & $75 \%$ & 4.0 & 2.0 & & 4.0 & 1.0 & \\
\hline
\end{tabular}

- Wilcoxon Signed Ranks Test 
$17.0 \pm 4.4$, for DPA and NDPA respectively; $p=0.094$ ) and Extroversion ( $14.5 \pm 4.3$ vs. $13.1 \pm 4.2$, for DPA and NDPA respectively; $p=0.269$ ).

\section{Cognitive patterns}

Mann-Whitney Test showed no differences between the DPA $(48.0 \pm 25.2)$ and NDPA $(42.2 \pm 19.6)$ groups, as assessed by the Brown ADD Scale $(p=0.527)$.

\section{Discussion}

Our original hypothesis, that nocturnal panic attacks represent a more severe form of panic disorder, was not supported by our data. In our study, nocturnal and diurnal panic attacks were similar in their phenomenology and outcome.

Our results corroborate the data of Craske et al, which found that nocturnal and diurnal panic attacks patients were equally distressed in terms of their panic disorder, comorbidity, general symptoms of negative affect, and interpersonal functioning. ${ }^{15}$ They suggested that nocturnal panic may represent one particular version of panic disorder (some panic patients mostly in public situations, some when alone, some when far from home, and some when asleep) that responds just as well as other forms of panic disorder to cognitive behavioral treatment. We found that they respond similarly to nortriptyline in low doses and over a short-time period, but the group of diurnal panic attack patients tended more often to require cognitive behavioral psychotherapy.

We found that nocturnal and diurnal groups did not differ in their symptomatological pattern, but both groups presented a high likelihood of prominent respiratory symptoms, suggesting an association of panic disorder with the Klein's suffocation false alarm theory. ${ }^{25}$

Cassano et al pointed out that nocturnal panic attack may be an atypical symptom that belongs to the concept of a panic spectrum. Although the precise "position" of nocturnal panic attacks in such a spectrum remains unknown (i.e., at the end or at the beginning; at the top or the base of the pyramid), we can observe that nocturnal panic attacks are similar to diurnal panic attacks in several aspects. ${ }^{14}$

Contrary to our original hypothesis, the experience of regular panic attacks during sleep does not indicate a more disabled group of patients. Instead, they may present more insomnia and anticipatory anxiety related to falling asleep. Although not statistically analyzed, it may be an atypical agoraphobic pattern that quickly responds to pharmacotherapy, according to our observation in daily clinical practice. On the other hand, the diurnal panic attacks group tended to present increased rates of patients submitted to cognitive behavioral therapy. These patients may present a more severe agoraphobic structure that may not be effectively treated with medications alone. Some authors $8,16,26$ have also found significantly increased rates of insomnia in nocturnal panic attacks. They pointed out an increased association of recurrent sleep panic attacks and comorbid major depression. This feature was not found in our sample.

Our study has several limitations, such as the small size of the sample and the fact that it was an open study, without a placebo or a control group, and without standardized dosages of the drug. Nevertheless, a follow-up evaluation after 30 days of treatment contributed to increase the validity of our data.

We conclude that, in our sample, the nocturnal and diurnal panic attacks do not differ from the only diurnal panic attacks in terms of respiratory symptoms, cognition, severity and low dose-short-term pharmacotherapy. These data may have clinical implications for PD prognosis, reducing the misdiagnoses and corroborating the categorical model of panic disorder. According to our data, it is not justified the tendency to put nocturnal panic attacks associated in an isolated group.

\section{Acknowledgments}

We are grateful to Professor Ivan Figueira, Department of Psychiatry, Universidade Federal do Rio de Janeiro, for his valuable comments and important suggestions for this study. Supported by the Brazilian Council for Scientific and Technological Development (CNPq), Grant 300500/93-9.

\section{References}

1. Barlow DH, Brown TA, Craske MG. Definitions of panic attacks and panic disorder in the DSM-IV: implications for research. J Abnorm Psychol. 1994;103(3):553-64.

2. Schmid NB, Forsyth JP, Santiago HT, Trakowski JH. Classification of panic attack subtypes in patients and normal controls in response to biological challenge: implications for assessment and treatment. J Anxiety Disord. 2002;16(6):625-38.

3. Aronson TA, Logue JM. Phenomenology of panic attacks: a descriptive study of panic disorder patients' self report. J Clin Psychiatry. 1988;49(1):8-13.

4. Briggs $A C$, Stretch DD, Brandon S. Subtyping of panic disorder by symptom profile. Br J Psychiatry. 1993;163:201-9.

5. Biber B, Alkin T. Panic disorder subtypes: differential responses to CO2 challenge. Am J Psychiatry. 1999;156(5):739-44.

6. Taylor CB, Sheikh J, Agras WS, Roth WT, Margraf J, Ehlers A, et al. Ambulatory heart rate changes in patients with panic attacks. Am J Psychiatry. 1986;143(4):478-82.

7. Craske MG, Barlow DH. Nocturnal panic. J Nerv Ment Dis. 1989;177(3): 160-7.

8. Mellman TA, Uhde TA. Patients with frequent sleep panic: clinical findings and response to medication treatment. J Clin Psychiatry. 1989;51(12):513-6.

9. Stein MB, Millar TW, Larsen DK, Kryger MH. Irregular breathing during sleep in patients with panic disorder. Am J Psychiatry. 1995; 152(8): 1 168-73.

10. Shapiro CM, Sloan EP. Nocturnal panic-an underrecognized entity. J Psychosom Res. 1998;44(1):21-3.

11. Edlund MJ, McNamara ME, Millman RP. Sleep apnea and panic attacks. Compr Psychiatry. 1991;32(2):130-2.

12. Lopes FL, Nardi AE, Nascimento I, Valença AM, Zin WA. Nocturnal panic attacks. Arq Neuropsiquiatr. 2002;60(3B):717-20.

13. Ley R. Panic attacks during sleep: a hyperventilation - probability model. J Behav Ther Exp Psychiatry. 1988;19(3):181-92.

14. Cassano GB, Frank E, Maser JD, Shear MK, Rotondo A, Mauri M, et al. The panic-agoraphobic spectrum. Hum Psychopharmacol Clin Exp. 1999;14:S38-S44.

15. Craske MG, Lang AJ, Mystkowski JL, Zucker BG, Bystritsky A, Yan-Go F. Does nocturnal panic represent a more severe form of panic disorder? J Nerv Ment Dis. 2002;190(9):611-8.

16. First MB, Spitzer RL, Gibbon M, Williams JBM. Structured Clinical Interview Diagnostic (SCID) for DSM-IV Axis I Disorders (Clinician Version) SCID-CV. Washington, DC: American Psychiatric; 1997.

17. American Psychiatric Association. Diagnostic and Statistical Manual for Mental Disorders - DSM-IV, $4^{\text {th }}$ ed. Washington, DC: American Psychiatric; 1994.

18. Shear MK, Brown TA, Barlow DH, Money R, Sholomskas DE, Woods SW, et al. Multicenter collaborative panic disorder severity scale. Am J Psychiatry. 1997;154(11):1571-5.

19. Barlow DH, Gorman JM, Shear MK, Woods SW. Cognitive behavioral therapy, imipramine or their combination for panic disorder. A randomized controlled trial. JAMA. 2000;283(19):2529-35. Erratum in: JAMA. 2000;284(19):2450. JAMA. $2001 ; 284(20): 2597$.

20. Shear MK, Rucci P, Williams J, Frank E, Grochocinski V, Vander Bilt $J$, et al. Reliability and validity of the Panic Disorder Severity Scale: replication and extension. J Psychiatric Res. 2001;35(5):293-6. 
21. Eysenck HJ. Eysenck Personality Inventory. The structure of human personality. London: Methuen; 1953.

22. Brown T. Brown ADD Scales. San Antonio: The Psychological; 1996.

23. Rucklidge JJ, Tannock R. Validity of the Brown ADD scales: an investigation in a predominantly inattentive ADHD adolescent sample with and without reading disabilities. J Atten Disord. 2002;5(3): 155-64.

24. Norton GR, Norton PJ, Walker JR, Cox BJ, Stein MB. A comparison of people with and without nocturnal panic attacks. J Behav Ther Exp Psychiatry. 1999;30(1):37-44.

25. Agargun MY, Kara H. Recurrent sleep panic, insomnia, and suicidal behavior in patients with panic disorder. Compr Psychiatry. 1998;39(3): 149-51.

26. Klein DF. False suffocation alarms, spontaneous panics, and related conditions. An integrative hypothesis. Arch Gen Psychiatry. 1993;50(4):306-17. 